\title{
THE STUDY OF GENETIC VARIABILITY IN ASSOCIATION WITH ZINC UPTAKE EFFICIENCY IN Triticum aestivum L GENOTYPES
}

\author{
Abdollah Hassanzadeh Ghorttapeh ${ }^{* 1}$, Aziz Majidi ${ }^{1}$, Javad Mozafari ${ }^{2}$ and Abdohosin \\ Zyaeian $^{3}$ \\ ${ }^{1}$ Horticulture Crops Department, West Azarbaijan Agricultural and Natural Resources Research and Education \\ Center, Agricultural Research, Education and Extinction Organization, (AREEO),Urmia, Iran \\ ${ }^{2}$ Agricultural Research, Education and Extinction Organization, Tehran, Iran \\ ${ }^{3}$ Soil and Water Research Institute (SWRI). AREEO, Karaj, Iran
}

\begin{abstract}
Diversity in agro ecosystems can improve the sustainability of cropping systems in terms of low external inputs and unpredictable climate changes. Agricultural ecosystems in the world are widely related to economical and social status. The major aim of agricultural ecosystems management is to maximize nutrient flow and human service materials. Nutrient efficiency in wheat is very complex. It includes nutrient acquisition efficiency and nutrient use efficiency. In this study 26 winter wheat genotypes were used to investigate the interactive effects between genotypes and the use efficiencies of the $\mathrm{Zn}$ micronutrient of the grain. An experiment was carried out in Agricultural and Natural Resources Research and Education, Center of West Azerbaijan, in which Genotypes were planted in complete randomized block design with three replications. The traits such as plant height, biological and grain yield, harvest index, length of spike, number of kernel per spike, thousand kernel weight and spike weight were measured or calculated. Concentration of $\mathrm{Zn}$ in the grain was measured by dry combustion using Perkin Elmer 2380 Atomic Absorption Spectroscopy. Zinc uptake was calculated by multiplying grain $\mathrm{Zn}$ concentration in the grain yield. It was revealed that biomass weight of whole plot, plant height, number of kernel per spike, grain yield of main culms, biological yield, length of spike and number of spikelet/spike were positively correlated with grain yield, while the grain protein percentage was negatively correlated with the grain yield. Variance analysis showed that there were highly significant differences among traits. The results obtained in this study indicate that nutrient use efficiency of the $\mathrm{Zn}$ varies widely within wheat genotypes. Some genotypes were identified as being $\mathrm{Zn}$ use efficiency. These are considered as lowinput genotypes. It seems that a special breeding programmer of crop cultivars for low Zn nutrient and stress condition could be successful. Improving the cultivar response to $\mathrm{Zn}$ nutrient will help to reduce inputs and hence protect the environment.
\end{abstract}

Keywords: Wheat, Zn use efficiency, Genetic variability, low input.

\section{Introduction}

Mineral elements play essential roles in biochemical and physiological functions of any biological system. In plants, appropriate mineral availability is necessary to every aspects of development including seed germination, seedling development (Welch, 1999), yield formation as well as mineral deposition in grain (Yilmaz et al., 1998; Welch, 1999).Deficiencies of elements such as zinc are well known in all cereals and cereal-growing countries. Increasing the quality of products in order to prevent malnutrition and some diseases caused by nutrient deficiencies, especially iron and zinc is very important. Achieving sustainable agricultural goals, it is possible to improve the quantity and quality of products via producing cultivars with desirable genetic traits. These cultivars are resistant to nutrient deficiencies and have high efficiency in nutrient uptakes (Hasanzadeh Gorttapeh and Mozafari, 2004). 
Wheat (Triticum spp.) is the major staple food crop in different parts of the world. It is cultivated in about half of areas in developing countries such as the Middle East, central India and the Mediterranean region of west Asia and the other countries including Ethiopia, Argentina, Chile, Russia, the United State, Italy, Spain and Canada. Generally, wheat production is low in developing countries due to usage low level inputs (e.g., fertilizer, water) in semi- arid regions. In addition, yields may be reduced by insects attacks, poor crop management and deficient weed control (Connor, 2011).Considering the high geographic diversity in different regions, it is necessary to evaluate the cultivars with different characteristics; then these crops should be applied in breeding programs to prevent the yield reduction and to raise nutrients uptake efficiency (Haneklaus and Schnug, 1993; Hassanzadeh Gorttapehand Salehzadehi, 2010). Yields of crops are often limited by low levels of mineral micronutrients in soil such as zinc $(\mathrm{Zn})$, especially in calcareous soils of arid and semiarid regions. Zinc deficiency in most agricultural soils of the country is a neglected point in production chain. High-yielding wheat varieties should be planted in fertile soils. They have lower yields than their potential due to lack of nutrients including Zinc. Since some of the nutrients may be lost or become inaccessible in various ways. Achieving the optimal yield per unit is possible by applying chemical fertilizers (Dambroth and Bassam. 1990).

The results of recent researches in different parts of the country have proven the effective role of this vital element in increasing the wheat quantity (Malkoti, 2001). Results relating to zinc fertilizers use, showed the low absorption of this element (less than 1\%) and different ability of cultivars in its absorption (Pecetti et al., 1992.). Studying the absorption of nutrients including Mg, Ca, K, P, N and Zn in 15 wheat cultivars, Sarik et al. (1990) found a high genetic diversity among wheat cultivars in terms of nutrientusage efficiency while some cultivars are more tolerant to its deficiency. Smith (1934) stated that the absorption of nutrients by the plant is influenced by genetic traits.

Breeding programs had a significant importance in terms of nutrient usage efficiency, plant characteristics, soil type and climatic factors. Haneklaus and Schnug (1993) observed a remarkable difference in the nutrients absorption, especially zinc, manganese and phosphorus in different wheat cultivars during their experiments. Investigating the different wheat varieties response to low-energy elements, Takar (1991) stated that deficiency of low-energy elements reduced the production potential in many soils of India. However, resistant cultivars application has been an effective step towards increasing products per unit area. Regarding demands for food, attempt should be focused in improving the quality and quantity of this product. Therefore, it is possible to assess desirable cultivars by identifying local lines with high efficiency of nutrient uptake, classifying favorable traits and determining the correlation between desirable traits and using them in breeding programs to correct high-yielding wheat cultivars and commercial cultivars.

The aim of this study was to introduce wheat varieties with high zinc uptake efficiency for cultivating and using in breeding programs. The results of this paper can be remarkable due to the limited sources of zinc and its deficiency in Iranian soil (Malkoti, 2001).

\section{Material and method}

Experiment was conducted at Research Station of Dr. Nakhjivani, West Azerbaijan Agricultural and Natural Resources Research and Esucation Center, Urmia, Iran. (Latitude $37^{\circ} 53^{\prime} \mathrm{N}$ and longitude $45^{\circ} 10^{\prime} \mathrm{E}$ and altitude $1325 \mathrm{~m}$ ) during the 2010 and 2011.The annual rainfall ranged from $300 \mathrm{~mm}$ to $350 \mathrm{~mm}$. The mean annual temperature was around $13.1^{\circ} \mathrm{C}$. The coldest and hottest months of year were December and July, respectively. The results showed that the irrigation water had a very low salinity and sodium which was in class c2s1 based on Will Cox classification. The site soil was non-saline, sandy loam with a small amount of lime and $\mathrm{pH} 8$. Phosphorus content was too low. 
Table 1 - Physico-chemical characteristics of the experimental site (Dr. Nakhjivani Research Station)

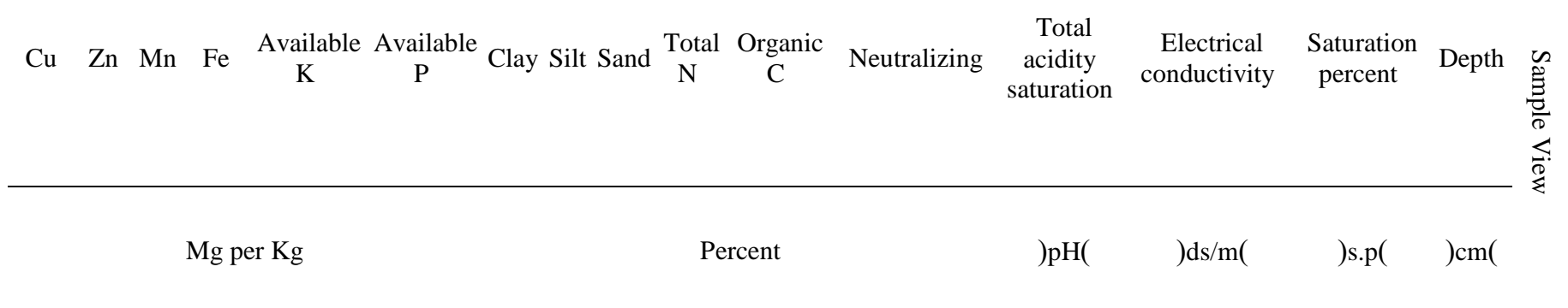

$\begin{array}{llllllllllllllllll}0.66 & 0.54 & 0.7 & 4.7 & 280 & 3.1 & 9 & 8 & 83 & 0.07 & 0.65 & 2.5 & 8 & 0.67 & 25 & 30-0\end{array}$

The field has been prepared in fall. After performing physic-chemical analysis (Table 1), required chemical fertilizers were distributed uniformly at the field. The experimental design was a split plot in a randomized complete block design with three replications. The experiment was consisted of seeds 23 selected lines and 3 common varieties (Alamut, Zarin and Shahryar). The first factor was consisted of three treatments: control (without fertilizer), consuming NPK, NPK $+\mathrm{Zn}$. The second factor was Seeds of lines and wheat cultivars. All crop managements were carried out and weeds were controlled with application of 2, 4-D (1.5 L/ha) in tiller stage. Traits such as biological and grain yield, harvest index and 1000 grain weight were measured at the end of the experiment. Zinc concentration was measured for the grain and zinc yield was calculated according to formula (1)

Zinc yield=zinc concentration $\times$ grain yield $/$ ha

Zinc absorption efficiency was calculated from the formula (2):

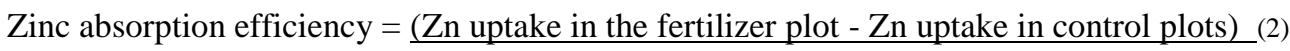

The amount of $\mathrm{Zn}$ fertilizer applied

Stress susceptibility index (SSI) was Calculated from formula (3)

$\mathrm{S}=1-(\mathrm{Ydi} / \mathrm{Ypi}) / 1-\mathrm{D}(3)$

$D=Y D / Y P$

Ydi=Mean yield under Zn deficiency (control without fertilizer)

Ypi=Mean yield after applying Zn fertilizer

$\mathrm{YD}=$ Mean yield of all lines under Zn deficiency (control without fertilizer),

$\mathrm{YP}=$ Mean yield of all lines after applying $\mathrm{Zn}$ fertilizer (non-stress) 
All data were statistically analyzed by the means of variance analysis followed by Duncan's multiple test. Simple correlations between traits were calculated and local lines were classified according to different characteristics and also environmental sensitivity index.

\section{Results and Discussion}

The results of analysis of variance are presented in Table 3. Based on the table, fertilizer and genotype effect were statistically significant on seed yield, biological yield, harvest index, 1000 grain weight, zinc concentration in seed and zinc yield per hectare, in probability level of $1 \%$.

Mean Comparison of traits in fertilizer treatments is presented in Table 4. Maximum grain yield, biological yield, harvest index and 1000 grain weight were achieved from NPK+Zn fertilizers treatment due to increasing nutrients uptake and photosynthesis rate. Moreover, Zn concentration in grain and its adsorption per unit area were highest.

Table 2- Number, code and collected site of lines and varieties

\begin{tabular}{lllllc}
\hline Collected site & Identification Code & $\begin{array}{c}\text { Genotype } \\
\text { number }\end{array}$ & Collected site & Identification Code & $\begin{array}{c}\text { Genotype } \\
\text { number }\end{array}$ \\
\hline Ardabil & Kc-330 & 14 & East Azerbaijan & Kc-20 & 1 \\
Ardabil & Kc-2143 & 15 & East Azerbaijan & Kc-30 & 2 \\
Ardabil & Kc-2147 & 16 & East Azerbaijan & Kc-40 & 3 \\
Ardabil & Kc-2149 & 17 & East Azerbaijan & Kc-44 & 4 \\
Ardabil & Kc-2151 & 18 & East Azerbaijan & Kc-50 & 5 \\
Ardabil & Kc-2155 & 19 & East Azerbaijan & Kc-58 & 6 \\
Khorasan & Kc-3079 & 20 & West Azerbaijan & Kc-113 & 7 \\
Khorasan & Kc-3095 & 21 & West Azerbaijan & Kc-132 & 8 \\
Khorasan & Kc-1717 & 22 & West Azerbaijan & Kc-145 & 9 \\
Khorasan & Kc-1773 & 23 & West Azerbaijan & Kc-1974 & 10 \\
West Azerbaijan & Alamut & 24 & Zanjan & Kc-4144 & 11 \\
West Azerbaijan & Zarin & 25 & Kurdistan & Kc-4173 & 13 \\
West Azerbaijan & Shahriyar & 26 & Kurdistan & Kc-4175 & 13 \\
\hline
\end{tabular}

Mean comparison of genotype on grain yield, biological yield, harvest index, 1000 seed weight, zinc concentration in seed and its yield are presented in Table 5. Maximum grain yield (6.9 ton/ha) was obtained from Shahriar cultivar, followed by Zarrin, East Azarbaijan (line 2), Kurdistan (genotype 12), Zanjan (genotype 11) and Ardebil (genotype 15) with4.09, 4.07, 3.99, 3.92 and 3.72 tons/h, respectively while the lowest grain yield $(2.5 \mathrm{t} / \mathrm{h})$ was achieved from khorasan (genotype 23$)$ cultivar.

The biological yield trend was similar to grain yield. Shahriar cultivar produced the highest yield among the studied genotypes. Zarrin and genotypes (2, 12 and 11) had the most biological yield, respectively. Biological yield in Ardebil and Khorasan was the lowest (Table 5).

Harvest index is an important characteristic that indicates the ratio of grain yield to biological yield. According to experiments, Selection based on harvest index increases grain yield and fertilization in plants (Viedt and Spanakakis, 1989.).

The highest 1000-seed weight was obtained from Shahriar and Zanjan (genotype 11), respectively which was significantly higher than the others (Table 5). This trait is one of the most important components of grain yield 
and its increase can improve the grain yield. The Zinc concentration in grain was significantly higher in genotypes 20 and 21 than the others.

This trait had the lowest amount in genotypes 1, 9 and 13, respectively. It showed diversity among genotypes in terms of $\mathrm{Zn}$ absorption and its storage. Genotypes with high ability for storing are more important. They have high quality in the food chain.

Mean comparison of $\mathrm{Zn}$ Yield (Zn concentration $\times$ grain yield) is shown in Table 5. The highest yield of zinc (31.8 kg ha-1) was produced in Shahriar cultivar due to its higher grain yield. This characteristic was lowest in genotypes $(3,23)$, respectively due to less grain yield or zinc adsorption per unit area. Regarding the results, wheat can absorb (122 to $318 \mathrm{~g} / \mathrm{h}$ ) zinc. Therefore, this element should be added to increase the soil fertility.

Table 3-Analysis of variance between Wheat cultivars with fertilizer treatments

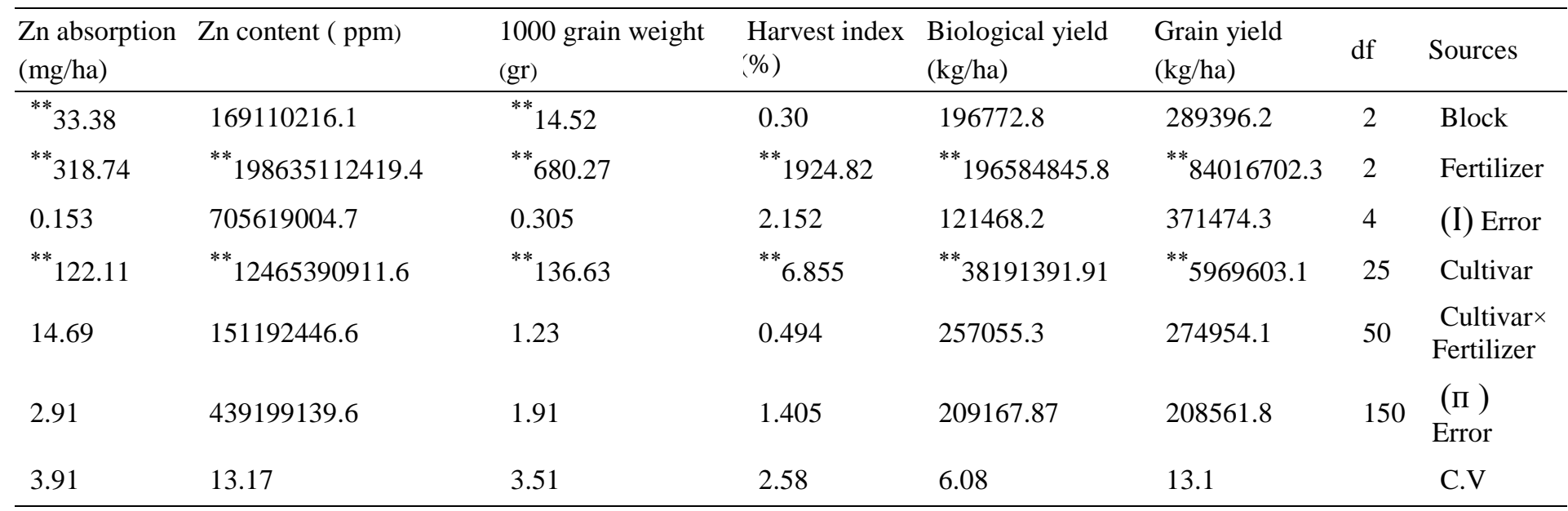

** means Significance in probability level of $1 \%$

The analyses of variance about zinc efficiency are presented in Table 6. Based on the table, genotype effect on zinc adsorption was statistically significant at $1 \%$. Mean Comparison of data showed that the zinc -use efficiency was higher in West Azarbaijan (genotype 10) among the others.

Table 4- mean Comparison of studied traits in fertilizer treatments

\begin{tabular}{|c|c|c|c|c|c|c|}
\hline $\begin{array}{l}\text { Zn absorption } \\
\mathrm{mg} / \mathrm{ha})(\end{array}$ & $\begin{array}{l}\text { Zn content } \\
\text { ) } \mathrm{ppm}(\end{array}$ & $\begin{array}{l}1000 \text { grain weight } \\
\text { ) gr ( }\end{array}$ & $\begin{array}{l}\text { Harvest index } \\
(\%)\end{array}$ & $\begin{array}{l}\text { Biological yield } \\
\mathrm{kg} / \mathrm{ha})\end{array}$ & $\begin{array}{l}\text { Grain yield } \\
(\mathrm{kg} / \mathrm{ha})\end{array}$ & treatment \\
\hline $45.70 \mathrm{~B}$ & $105356 \mathrm{C}$ & $36.08 \mathrm{C}$ & $40.23 \mathrm{C}$ & $5741.32 \mathrm{C}$ & $2308.7 \mathrm{C}$ & No Fertilizer \\
\hline $48.01 \mathrm{~A}$ & $205440 \mathrm{~A}$ & $41.80 \mathrm{~A}$ & 49.39A & 8786.29A & 4299.1A & consuming NPK $+\mathrm{Zn}$ \\
\hline
\end{tabular}

Similar letters indicates no significant difference in probability level of $5 \%$ in each column. 
Table 5 mean Comparison of studied traits in wheat genotype

\begin{tabular}{|c|c|c|c|c|c|c|}
\hline $\begin{array}{l}\text { Zn absorption } \\
\mathrm{mg} / \mathrm{ha})(\end{array}$ & $\begin{array}{l}\text { Zn content } \\
\mathrm{Mg} / \mathrm{kg})(\end{array}$ & $\begin{array}{l}\text { 1000grain weight } \\
\operatorname{gr}(\end{array}$ & $\begin{array}{l}\text { Harvest index } \\
) \%(\end{array}$ & $\begin{array}{l}\text { Biological yield } \\
\mathrm{kg} / \mathrm{ha})(\end{array}$ & $\begin{array}{l}\text { Grain yield } \\
(\mathrm{kg} / \mathrm{ha})\end{array}$ & Genotype \\
\hline $133045 \mathrm{IJ}$ & $36.21 \mathrm{Y}$ & $34.6 \mathrm{~K}$ & 46.48ABCDE & 7405.3DEFG & $3501.5 \mathrm{CDE}$ & 1 \\
\hline 193915B & $46.85 \mathrm{~K}$ & $36.98 \mathrm{HI}$ & 46.18BCDEF & 8749.1B & $4074.1 \mathrm{~B}$ & 2 \\
\hline $12239 \mathrm{~J}$ & $43.12 \mathrm{U}$ & $35.28 \mathrm{JK}$ & 45.27EFGH & $6128 \mathrm{KL}$ & $2818.7 \mathrm{GH}$ & 3 \\
\hline 135466IJ & $43.35 \mathrm{~S}$ & $37.49 \mathrm{GHI}$ & 45.90DEFG & 6688.3HIJ & 3126.2EFG & 4 \\
\hline 137924HIJ & $47.25 \mathrm{~J}$ & $38.15 \mathrm{GH}$ & 44.97FGH & $6332.3 \mathrm{JK}$ & 2890.4FGH & 5 \\
\hline 151870DEFGHI & $49.62 \mathrm{C}$ & $43.33 \mathrm{C}$ & 45.55DEFG & 6776.9HIJ & 3135.8EFG & 6 \\
\hline 160642CDEFGH & 47.39I & $42.76 \mathrm{CD}$ & 46.39ABCDE & 7140.6EFGH & 3376.4DEF & 7 \\
\hline 164197CDEFGH & $45.10 \mathrm{~N}$ & $41.28 \mathrm{EF}$ & 45.91CDEF & 7566.6DE & $3522.7 \mathrm{CDE}$ & 8 \\
\hline 149789EFGHI & $42.75 \mathrm{~W}$ & $43.36 \mathrm{C}$ & 47.06АBC & 7076.7FGH & 3394.4DEF & 9 \\
\hline 168166CDEF & $48.85 \mathrm{E}$ & $38.51 \mathrm{G}$ & 45.52DEFG & 7447.9DEF & 3446.3CDE & 10 \\
\hline $176972 \mathrm{BC}$ & 44.22Q & 46.07B & 44.93FGH & $8596.3 \mathrm{~B}$ & $3928.3 \mathrm{BC}$ & 11 \\
\hline 172959BCD & $43.93 \mathrm{R}$ & $43.75 \mathrm{C}$ & $45.43 \mathrm{EFG}$ & $8712.1 \mathrm{~B}$ & 3997.0B & 12 \\
\hline 142022GHIJ & $40.25 X$ & 41.72DEF & 45.59DEFG & 7431.8DEF & 3444.1CDE & 13 \\
\hline 1551143DEFGHI & $43.33 \mathrm{~T}$ & $37.02 \mathrm{HI}$ & 47.01ABC & 7308.5EFG & 3494.4CDE & 14 \\
\hline 170778CDE & $45.42 \mathrm{M}$ & 42.61CD & 45.59DEFG & $8038.8 \mathrm{C}$ & 3718.1BCD & 15 \\
\hline 146167FGHI & $48.28 \mathrm{G}$ & $37.55 \mathrm{GHI}$ & 45.44EFG & 6549.9IJK & 3021.7EFGH & 16 \\
\hline $131461 \mathrm{IJ}$ & $45.10 \mathrm{~N}$ & $34.89 \mathrm{~K}$ & $44.45 \mathrm{GH}$ & 6676.6HIJ & 3007.1EFGH & 17 \\
\hline 139441HIJ & $44.59 \mathrm{P}$ & $34.72 \mathrm{~K}$ & 46.03CDEF & $6570.0 \mathrm{IJK}$ & 3068.4EFGH & 18 \\
\hline 147619EFGHI & 44.890 & $36.95 \mathrm{HI}$ & 46.97ABC & $6426.0 \mathrm{JK}$ & 3189.8EFG & 19 \\
\hline 138164HIJ & $54.89 \mathrm{~A}$ & $37.08 \mathrm{GHI}$ & $47.65 \mathrm{~A}$ & $5686.8 \mathrm{~L}$ & $2764.4 \mathrm{GH}$ & 20 \\
\hline 170854CDE & 51.94B & $36.29 \mathrm{IJ}$ & $47.36 \mathrm{AB}$ & 6948.7GHI & 3352.2DEF & 21 \\
\hline 166666CDEF & $48.72 \mathrm{~F}$ & $36.39 \mathrm{IJ}$ & 46.82ABCD & 7797.3CD & 3371.2DEF & 22 \\
\hline $122232 J$ & $47.77 \mathrm{H}$ & $36.48 \mathrm{IJ}$ & $44.14 \mathrm{H}$ & $5708.8 \mathrm{~L}$ & $2577.5 \mathrm{H}$ & 23 \\
\hline 149575EFGHI & 49.48D & $40.86 \mathrm{~F}$ & 45.93CDEF & $6408.3 \mathrm{JK}$ & 3020.5EFGH & 24 \\
\hline $176533 B C$ & $42.75 \mathrm{~V}$ & $40.73 \mathrm{~F}$ & 26.01CDEF & 8800.9B & 4097.9B & 25 \\
\hline $318132 \mathrm{~A}$ & $46.52 \mathrm{~L}$ & $48.44 \mathrm{~A}$ & 45.33EFGH & $16632.4 \mathrm{~A}$ & $6946.9 \mathrm{~A}$ & 26 \\
\hline
\end{tabular}

Similar letters indicates no significant difference in probability level of $5 \%$ in each column.

Table 6- Mean comparison of Zn- use efficiency and stress susceptibility index in different genotypes at 5\%

$$
\text { MS }
$$

\begin{tabular}{llll} 
SSI & Zn- use efficiency & df & Sources \\
\hline 1.7518 & 0.1702 & 2 & Replication \\
1.8865 & $0.4464 * *$ & 25 & Cultivar \\
1.1756 & 0.10570 & 50 & Error \\
3.60 & 15.84 & & $\mathrm{CV}$ \\
\hline
\end{tabular}

means Significance in probability level of $1 \% * *$

Statistically, this genotype didn't have any difference with most of genotypes except 6, 13, 18, 21 and 25. Khorasan cultivar (genotype 21) had the lowest zinc efficiency (Table 7). Researchers mentioned the effects of 
genotype and environment, including climatic and soil conditions, as effective factors in the absorption and storage of nutrients (Sorm, 1984).

Table 7- mean comparison of Zn- use efficiency in different genotypes at $5 \%$

\begin{tabular}{llll}
\hline Zn- use efficiency & Genotype & Zn- use efficiency & Genotype \\
\hline $0.7343 \mathrm{ABCDE}$ & 14 & $1.0177 \mathrm{AB}$ & 1 \\
$0.6950 \mathrm{ABCDE}$ & 15 & $0.9542 \mathrm{AB}$ & 2 \\
$0.7585 \mathrm{ABCD}$ & 16 & $0.5985 \mathrm{ABCDE}$ & 3 \\
$0.1873 \mathrm{DEF}$ & 17 & $0.8326 \mathrm{ABC}$ & 4 \\
$0.7518 \mathrm{ABCD}$ & 18 & $0.8169 \mathrm{ABCD}$ & 5 \\
$1.0292 \mathrm{AB}$ & 19 & $0.4353 \mathrm{BCDEF}$ & 6 \\
$0.1116 \mathrm{~F}$ & 20 & $1.0411 \mathrm{AB}$ & 7 \\
$0.7675 \mathrm{ABCD}$ & 21 & $0.9284 \mathrm{AB}$ & 8 \\
$0.9530 \mathrm{AB}$ & 22 & $1.087 \mathrm{~A}$ & 9 \\
$0.2305 \mathrm{CDEF}$ & 23 & $0.5958 \mathrm{ABCDE}$ & 10 \\
$0.4932 \mathrm{ABCDEF}$ & 24 & $0.7188 \mathrm{ABCDE}$ & 11 \\
$0.6302 \mathrm{ABCDE}$ & 25 & $0.1057 \mathrm{FG}$ & 12 \\
$1.025 \mathrm{AB}$ & 26 & $0.8491 \mathrm{ABC}$ & 13 \\
\hline
\end{tabular}

Investigating of different genotypes based on stress susceptibility index (Fisher and Maurer, 1984)

The genotypes were classified based on stress susceptibility index(Fisher and Maurer,1984).Based on this coefficient, since the difference of genotype yields under stress conditions is less than normal condition or the obtained number is closer to 1 , this genotype is more resistant to environmental stress. According to the results of this study, genotypes were classified in three groups: resistant (1-3), semi-sensitive (3-6) and sensitive (more than 6). The numbers and classifications of each group are presented in Table 9. Khorasan cultivar (genotype No. 22) was the most sensitive to zinc deficiency. Zarrin and Shahriar were more resistant than other genotypes and the remaining genotypes were placed in semi-sensitive group. Correlation coefficients between the measured traits are presented in Table 9. Grain yield had a significant and positive correlation with biological yield and 1000 grain weight and their increasing can improve grain yield. The zinc use efficiency and its concentration in grain, grain yield and zinc yield had positive and significant correlation $(\mathrm{p}<0.95)$, which meant improve zinc use efficiency by increasing each of them.

Increasing quality of food along with preserving the environment is one of the main goals in today's societies. In this regard, increasing soil fertility and preventing nutrients losing plays an important role in improving the quantity and quality of products. However, the quality of soil and environment should be protected in sustainable agriculture. Different factors have significant impacts on soil fertility such as type of cultivated product and the previous product, planting date (spring or autumn), amount of nutrients in soil, physical characteristics of the soil (texture and drainage), the purpose of planting (forage, grain, or dual purpose) and genotype type (7). 
Table 8- classifying genotypes based on stress- susceptibility index (Fisher and Maurer, 1984)

\begin{tabular}{llllll}
\hline Class & SSI & Genotype & Class & SSI & Genotype \\
\hline Semi-sensitive & 3.65 & 14 & Semi-sensitive & 3.46 & 1 \\
Semi-sensitive & 3.50 & 15 & Semi-sensitive & 3.80 & 2 \\
Semi-sensitive & 3.68 & 16 & Semi-sensitive & 3.53 & 3 \\
Semi-sensitive & 3.58 & 17 & Semi-sensitive & 3.49 & 4 \\
Semi-sensitive & 3.57 & 18 & Semi-sensitive & 3.49 & 5 \\
Semi-sensitive & 3.92 & 19 & Semi-sensitive & 3.56 & 6 \\
Semi-sensitive & 3.73 & 20 & Semi-sensitive & 3.56 & 7 \\
Semi-sensitive & 3.59 & 21 & Semi-sensitive & 3.57 & 8 \\
sensitive & 6.50 & 22 & Semi-sensitive & 3.86 & 9 \\
Semi-sensitive & 3.43 & 23 & Semi-sensitive & 3.36 & 10 \\
Semi-sensitive & 3.52 & 24 & Semi-sensitive & 3.68 & 11 \\
Resistant & 2.38 & 25 & Semi-sensitive & 3.70 & 12 \\
Resistant & 2.54 & 26 & Semi-sensitive & 3.478 & 13 \\
\hline
\end{tabular}

Table 9: correlation coefficient between wheat lines and cultivars in measured traits

\begin{tabular}{|c|c|c|c|c|c|c|c|c|}
\hline traits & 1 & 2 & 3 & 4 & 5 & 6 & 7 & 8 \\
\hline 1. grain yield & 1 & & & & & & & \\
\hline 2. Biological yield & $* * 0.993$ & 1 & & & & & & \\
\hline 3. Harvest index & -0.053 & $0.121-$ & 1 & & & & & \\
\hline 4. 1000 grain weight & $* * 0.637$ & $* * 0.624$ & $0.175-$ & 1 & & & & \\
\hline 5. Zn content & $0.147-$ & $0.119-$ & 0.165 & $0.018-$ & 1 & & & \\
\hline 6. $\mathrm{Zn}$ absorption & $* * 0.962$ & $* * 0.962$ & $0.014-$ & $* * 0.633$ & 0.109 & 1 & & \\
\hline 7. $\mathrm{Zn}$ - use efficiency & $*_{0.321}$ & $*_{0.289}$ & $*_{0.349}$ & 0.124 & $*_{0.362}$ & $*_{0.294}$ & 1 & \\
\hline 8. SSI & $*_{0.319-}$ & $*_{-0.285}$ & $*_{0.304}$ & $*_{0.296-}$ & 0.187 & $0.239-$ & 0.133 & 1 \\
\hline
\end{tabular}

**and* means significance at $1 \%$ and $5 \%$, respectively

The genotype is one of the main factors influences the products. Genotypes with ability of high nutrients absorption and storing them in their organs can enhance the quality of product and prevent malnutrition or some nutritional deficiency diseases. Moreover, cultivation of these genotypes can lead to less fertilizer use. $\mathrm{Zn}$ element has a significant role in raising production and quality improvement among the nutrients. Based on results of the paper, there was a high diversity in grain yield, biological yield, harvest index, $\mathrm{Zn}$ absorption and 
its yield among genotypes (Table 8). Genetic potential of genotypes is a determinant of environmental factors in optimal use and genotypes 2, 11, 12, 25 and 26 were the best in this regard. Some researchers also suggested that the yield potential varies among cultivars and local lines. The absorption and storage of nutrients were different among them $(1,2,3,4,5,7$ and 10).Zinc- uptake efficiency differed among genotypes and those which absorbed more $\mathrm{Zn}$ element were more efficient (1, 2, 7, 8, 9, 19, 22 and 26). According to experiments, genotypes that responded to low levels of nutrients could be used to improve crops and produce high potential cultivars (9, 17, 21 and 19). Improving wheat cultivars in order to absorb more elements can increase the efficiency of low-energy elements adsorption in soil.

Finally, based on cluster method, treatments were placed in three main groups.

Samples with high seed yield, high Zn use efficiency and low susceptibility to its deficiency: shahriyar cultivar.

Samples with fairly high seed yield, fairly $\mathrm{Zn}$ use efficiency: 7, 21, 26, 42, 53, 56, 71, 89, and 94: Zarrin cultivar.

Samples with low seed yield, low Zn use efficiency: 4, 10, 12, 16, 20, 33, 68, 13, 74, 76, 77, 80, 83 and 100: Almut clutivarl.

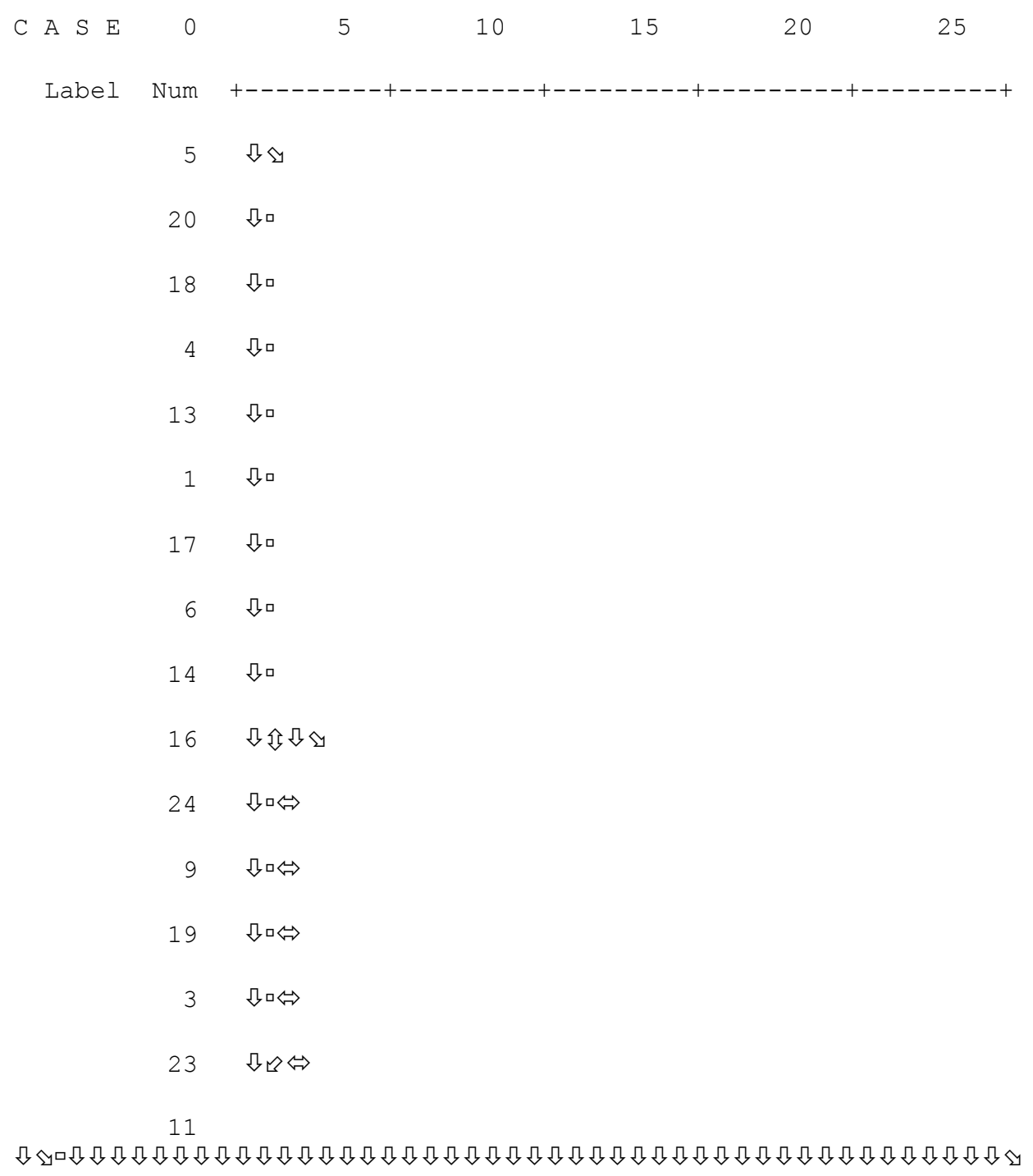




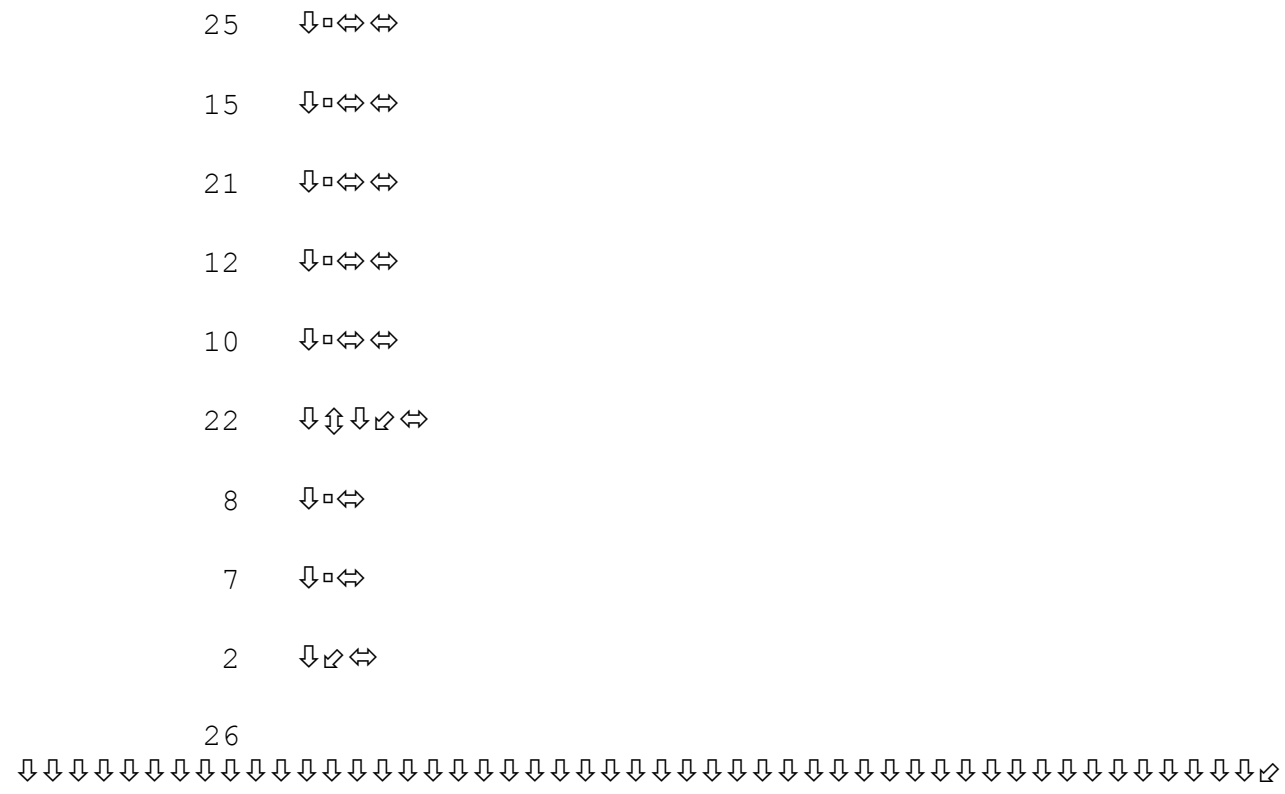

Table 3-Dendrogram of the studied treatments

Sarik and Momsilovich (16) reported increasing fertilizer use efficiency by examining the nitrogen uptake efficiency among wheat genotypes. The zinc element investigation in stress susceptibility index showed that genotypes 25 and 26 were highly resistant and genotype 22 was very sensitive (Table 11). The resistant genotypes can be used in breeding programs.

\section{Conclusion}

Increasing the quality of food along with preserving the environment damage is among the main goals in sustainable agriculture. It has been proven that increasing soil fertility and preventing the nutrients loss lead to improve quality and quantity of products. Distinct factors impact on soil fertility including type of crop(forage, grain or both of them), previous crop, cultivation date, nutrients content in soil and type of genotype. Genotype is the main factor in improving the quality and quantity of products.

Based on this paper, there was a great diversity in grain yield, biological yield, harvest index, $\mathrm{Zn}$ absorption and its yield (table 9). Also, the genetic potential was the most important factor in optimal use.Zarrin and Shahriyar cultivars were the best in condition of samples No. 7, 53 and 56. Some researchers stated that yield potential is different among cultivars and local lines. Moreover, absorption and storage of nutrients are various (Altin and Frey, 1990; Dambroth and El Bassam, 1990; Damisch and wilberg, 1991; Fichbeck, 1988; Haneklaus and Schnug, 1993; hassanzadeh-Gorttapeh, 2007) as well as Znuse efficiency. Samples with higher ability toabsorb nutrient (Zn) had the highest efficiency (genotypes 4, 7, 10, 26, 33, 80, 94 and Shahriyar cultivar).

Superior genotypes or genotypes which react to low levels of nutrients can be used in breeding programs. As a result, high potential lines can be produced while increasing the efficiency of low-input elements. Saric and Momcilovic (2004) showed increasing the efficiency of fertilizer application by examining the Nuse efficiency in superior lines. Investigating SSI indicated that Zarrin and Shahriyar cultivars were very tolerant and genotype 94 was sensitive. Resistant and sensitive cultivars have a great importance in breeding activities. Takkar (2001) stated that superior genotypes should be considered and produced in order to prevent malnutrition.

According to this paper, it seems that it is possible to modify and produce cultivars to increase the quality of production in low nutrient conditions. Appling this method, we can significantly reduce consumption of 
fertilizer in agriculture and prevent the environment damage. Furthermore, it is possible to select genotypes with high efficiency in nutrients absorption and storage (i.e. zinc) using modern technologies and biotechnologies such as RAPDs, RFLPs and PCRs due to genetic variation among genotypes.

\section{Suggestions}

1-Considering the different susceptibility of wheat genotypes to zinc element, it is recommended to pay attention to the specific sensitivity of plants at the time of fertilizer consuming.

2- It is suggested to investigate uperior genotypes for absorbing different amounts of fertilizer and obtaining accurate results about selection of efficient cultivars.

3- It is also important to study the selection of best genotypes in order to reduce the inputs (fertilizers, water, etc.) per unit area

\section{References}

Altin, G. N. and K.J. Frey. 1990. Breeding crop varieties for low input agriculture. Am. J. Alt. Agric., 4, 53-58. Austin, R.B. 1988. A different ideotype for each environment? In: M. L. Jorna and L.A.J. Slootmaker(9eds.), Cereal breeding related to integrated cereal production. Proceedings of the EUCARPIA Conference, Pp.47-60. PUDOC, Wageningen. The Netherlands.

Dambroth, M. and N. El Bassam. 1990. Genotypic variation in plant productivity and consequences for breeding of low-input cultivars. In: Proceeding of International Symposium on Genetic Aspects of Plant Mineral Nutrition. Kluwer Academic Publishers. The Netherlands. Pp. 1-7.

Damisch, W. and A. Wiberg. 1991. Biomass yield- A topical issue in modern wheat breeding programmes. Plant Breeding 107, 11-17.

Fischbeck, G. 1988. Cereal breeding related to integrated cereal production. Proceedings of the EUCARPIA Conference, pp.9-27. PUDOC, Wageningen. The Netherlands.

Fischer, R., and R. Maurer. 1978, Drought resistance in spring wheat cultivars: I. Grain yield responses. Aust. J. Agric. Res. 29: 897-912.

Haneklaus, S., and E.Schnug 1993. Genetic variability and pattern of mineral nutients of Triticumaestivum and Brassica napus. Aspects of Applied Biology., 34, 211-218.

HasanzadehGorttapeh, A. and J. Mozafari. 2004. Toward sustainable agriculture with cultivar selection and evaluation for low input. In: Proceeding of Third National Biological fertilizer and Optimal Use of Fertilizer and Poison in Agriculture. Karaj, Iran, pp.204-205.

HassanzadehGorttapeh, A., A. Galavand, and M. Zahedmanesh, 2006. Effects of organic, inorganic and integrated fertilizer systems on yield and agronomic N-efficiency of sunflower cultivars. In: Proceedings of 18th International Soil Meeting (ISM) on Soil Sustaining Life on Earth, Managing Soil and Technology. Harran university, Urfa, Turkey, pp.922-927.

HassanzadehGorttapeh, A. and A. Ebadi. 2007. Effects of organic, inorganic and integrated fertilizer systems on the zinc absorption and yield of sunflower cultivars. Procedings of the Zinc Crops 2007, International Conference, Istanbul, Turkey. Pp 204-206.

HassanzadehGorttapeh, A. and H. Salehzadehi. 2010. Biodiversity in natural and agricultural ecosystems. Pub. JahadDaneshgahi, Urmia, Iran.

Javadat, A.A. 1990. Levels of phenotypic variation for developmental traits in landrace genotypes of durum wheat from Jordan. Euphytica, 5, 265-271.

Malkoti, M.J. 2001. Wheat fertilizer. Agriculture Extension Pub. Kraj, Iran.

Pecetti, L., A.B Damania, and G. Kashour. 1992. Geographic variation for spike and graincharacteristics in durum wheat germplasm adapted to dryland condition. Genetic Resources and Crop Evolution, 39: 97-105.

Rechinger, K.H.1970. floraIranica No.70, AkademisheDruck- U., Verlagsanstalt, Graz -Austria. 
Saric , M . R ., S . K. Momcilovic.1990. Genetic diversity among wheat cultivars in relation to concentration of the nutrition elements. In: Proceedings of the International Congress of Plant Physiology New Delhi , India, 2, 1169 - 1171 .

Schinkel B. and W. Mechelk.1990. A method to estimate the prospect of specific breeding for nutrient efficiency. In: Proceeding of International Symposium on Genetic Aspects of Plant Mineral Nutrition. Kluwer Academic Publishers. The Netherlands, pp. 449-456.

Smith, N. S. 1934. Response of inbred lines crosses in maize to variations of nitrogen and phosphorus supplied as nutrients. J. Am. Soc .Agron., 26, 775- 780.

Spanakakis, A., 1990. Grain yield and quality characters of genotypes in F2 germination under low and high nitrogen input. In: proceeding of International Symposium on Genetic Aspects of Plant Mineral Nutrition. Kluwer Academic Publishers. The Netherlands. pp. 456-464.

Takkar, P.N. 1991. Requirement and response of crop cultivars to micro-nutrients in India-a review. In: Proceeding of The Fourth International Symptoms of Genetic Aspects of Plant Mineral Nutration.,341-348. Australia.

Viedt, A. and A. Spanakakis, 1989. Breeding wheat varieties with improved nitrogen utilization I. Performance of winter wheat varieties under reduced nitrogen condition. Vortage Fur Pflanzenzuchtung, 15: 23-28.

Wanies, J.G. 1989. Genetic variation, heritability and path-analysis inlandraces of bread wheat from southwestern Iran. Euphytica, 41, 183 -190.

Connor D.J, Loomis R.S, Cassman KG. 2011. Crop ecology: productivity and management in agricultural systems. Cambridge University Press. 